\title{
Penerapan Data JSON Untuk Mendukung Pengembangan Aplikasi Pada Perguruan Tinggi Dengan Teknik Restfull Dan Web Service
}

\author{
Ary Budi Warsito ${ }^{1}$ \\ Ajeng Ananda ${ }^{2}$ \\ Dian Triyanjaya ${ }^{3}$ \\ Jl. Jendral Sudirman No. 40, Modernland, Tangerang \\ Email:arybudiwarsito@raharja.info ${ }^{1)}$ Ajeng@rahraja.info ${ }^{2)}$ dian.triyanjaya@rahraja.info ${ }^{3}$
}

\begin{abstract}
ABSTRAK
Data adalah salah satu komponen penting dalam sebuah aplikasi. Di perlukan sebuah database untuk menyimpan data dalam jumlah besar sebagai media pendistribusian data dari server ke client. Banyak nya aplikasi pada sebuah perguruan tinggi membutuhkan bandwidth yang besar untuk keperluan pengambilan data untuk di sajikan sebagai sistem informasi yang sangat berguna untuk berbagai kepentingan. Web Service sangat berperan penting pada kasus ini dimana, client yang seharusnya mengakses melalui jalur yang berbeda ke database akan di alihkan ke dalam web service dalam proses pengambilan data untuk meringankan kerja database yang harus berulang ulang melayani permintaan dari client. Arsitektur REST, yang pada dasarnya di oprasikan melalui HTTP (Hypertext Transfer Protocol), yang mengacu pada proses pembacaan halaman web tertentu yang berisi sebuah file JSON. File inilah yang menguraikan dan memuat konten yang hendak disajikan kepada konsumen. Setelah melalui sebuah proses definisi tertentu, konsumen akan bisa mengakses antarmuka aplikasi yang tersedia.
\end{abstract}

Kata Kunci : Database, Web Service, permintaan

\begin{abstract}
Data is one of the important components in an application. In need of a database to store large amounts of data as a medium for the distribution of data from the server to the client. Many of its application on a college requires a large bandwidth for data retrieval purposes to served as an information system that is very useful for various purposes. Web Service is very important in this case where, clients should access through different pathways to the database will switch to the web service in the data collection process to alleviate the database that should be repeated requests from the client. REST architecture, which is basically in oprasikan via HTTP (Hypertext Transfer Protocol), which refers to the process of reading a specific web page that contains a JSON file. It is this file that describes and includes the content to be presented to consumers. After going through a process of certain definitions, consumers will be able to access the application interface is available.
\end{abstract}

Keywords: Database, Web Service, request

26 | Ary, Ajeng, Dian - PenerapanData JSON Untuk Mendukung Pengembangan ... 


\section{PENDAHULUAN}

Saat ini, web service telah menjadi makin di populerkan oleh para pengembang aplikasi. Teknologi web service adalah merupakan salah satu metode setiap fungsi bisnis untuk dapat berkomunikasi. Bukan seperti model client/server tradisional pada umumnya, seperti web server atau sistem halaman web namun Web service tidak menyediakan GUI untuk para penggunanya. Web service hanya memberikan business logic, proses, dan data dalam program interface antar jaringan. Web services sudah tidak memerlukan browser atau HTML. oleh karena itu berikutnya Web service dapat di masukan ke dalam sebuah GUI (graphic user interfaces). Web service adalah sebuah sofware aplikasi yang tidak terpengaruh oleh platform, ia akan memberikan data-data yang dapat diakses oleh client. oleh karena itu web service juga akan menggunakan JSON untuk pertukaran data, terutama dalam dua entities bisnis yang pastinya berbeda. Di sisi lain pengertian dari Web Service itu sendiri dapat di sebut bahwa Web service adalah sistem perangkat lunak yang di buat demi mendukung interopabilitas mesin-kemesin yang mampu berinteraksi melalui sebuah jaringan. Web service memiliki tampilan yang di paparkan dalam format mesin-processable (khusus WSDL). Sistem lain berinteraksi dengan Web service dalam cara ditentukan oleh deskripsi dengan menggunakan pesan SOAP, biasanya disampaikan menggunakan HTTP dengan serialisasi JSON dalam hubungannya dengan Web lainnya yang terkait, dengan memahami ketiga komponen tersebut sebenarnya pembuatan web service itu relatif sangat mudah namun di perlukan berbagai pemahaman tentang logika php untuk membantu jalannya web service tersebut.

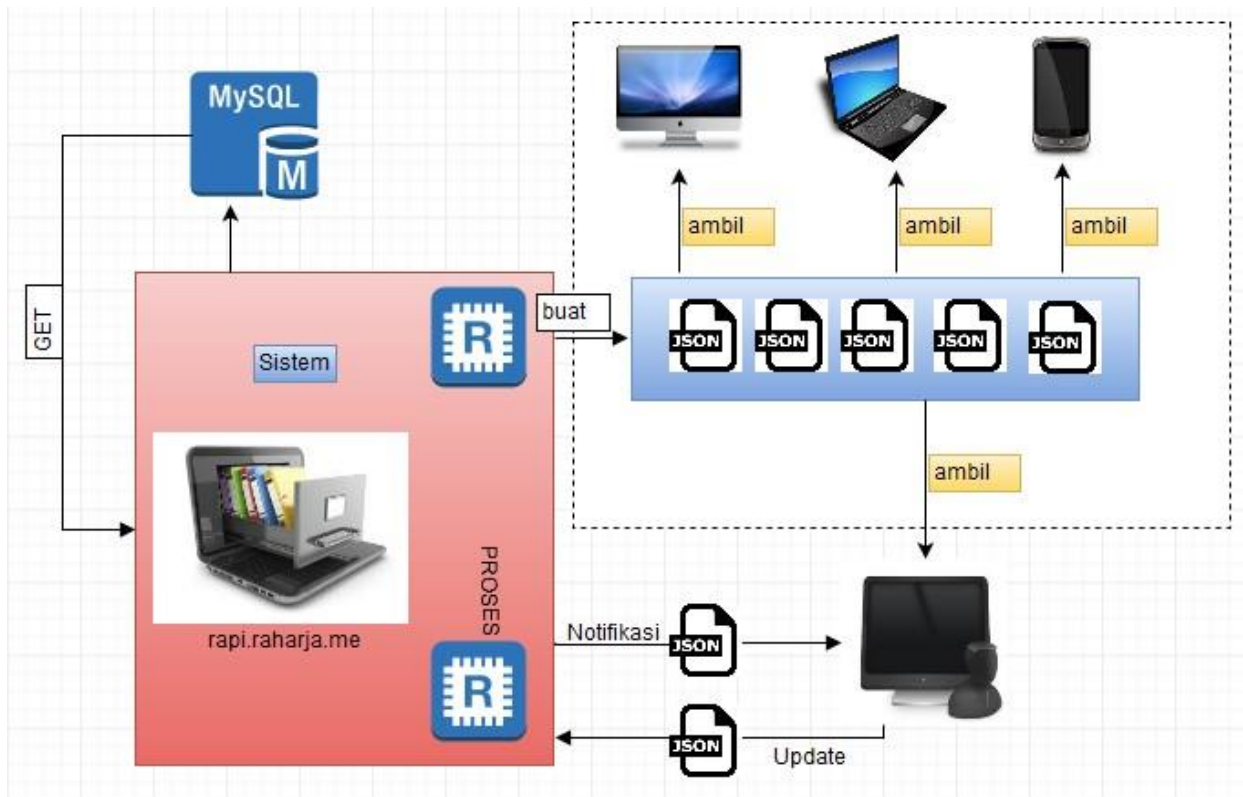

Gambar 1. Konsep Web Service. 


\section{PERMASALAHAN}

Pada pembuatan aplikasi di perguruan tinggi ada 2 kendala yang sering terjadi, yang pertama dari segi mahasiswa dan yang ke dua dari segi Staff Database Manager. Dari segi mahasiswa, adapun masalah yang terjadi berulang-ulang saat mahasiswa hendak meminta request data ke database untuk keperluan aplikasi mereka, maka mahasiswa harus request kepada staff dan membuat perjanjian berapa lama durasi pemakaian data tersebut di karnakan banyaknya aplikasi pada perguruan tinggi yang menggunakan database tersebut dan yang terjadi seringnya penolakan dari pihak staff di karenakan masalah keamanan dan efektifitas penggunaan bandwidth demi kelancaran transfer data untuk sistem lain.

Dari segi Staff Database Manager, dan selanjutnya permaasalahan lain ada di pihak staff yang bertugas sebagai database manager, saat mahasiswa request untuk mengakses database staaf harus memahami dulu maksud dan tujuan mahasiswa tersebut untuk keperluan apa database tersebut di gunakan untuk meminimalisir penyalah gunaan database pada perguruan tinggi.

\section{METODE PENELITIAN}

Dalam melakukan penelitian yang membahas tentang pemanfaatan RESTful API ini, metode yang di gunakan adalah studi kasus yang di lakukan pada perguruan tinggi sebagai lingkup penelitian ini. Tujuan penelitian studi kasus khusus menjelaskan dan memahami tentang pembuatan file JSON. Adapun tujuan lain yang berkaitan dengan hal mengenai Web Service, bahwa tujuan penggunaan penelitian studi kasus ini adalah tidak hanya untuk menjelaskan untuk apa obyek tersebut di teliti, akan tetapi bertujuan untuk mendeskripsikan bagaimana keberadaan masalah tersebut dan mengapa masalah tersebut dapat terjadi di perguruan tinggi raharja.

\subsection{Literature Review}

Untuk mendapatkan hasil yang memuaskan dalam upaya penerapan data JSON untuk mendukung teknik RESTful API pada aplikasi Web Service sebagai media dalam pengembangan aplikasi, oleh sebab itu tentunya sudah banyak sekali penelitian yang mengkaji perihal ini, di bawah ada beberapa diantaranya adalah sebagai berikut :

1. Penelitian yang di lakukan oleh I Wayan Gede Suma Wijaya, pada tahun 2012 yang berjudul "Penerapan Web Service Pada Aplikasi Sistem Akademik Pada Platform Sistem Operasi Mobile Android" Informasi akademik dan perkuliahan menjadi kebutuhan yang penting bagi mahasiswa. Seperti informasi tentang nilai, jadwal kuliah, jadwal kehadiran dosen dan sebagainya. Dengan informasi yang terdistribusi dengan baik, maka tidak akan terjadi 
kesalahpahaman bahkan buntunya penyebaran informasi yang bersifat penting. Informasi biasanya disebarkan secara konvensional melalui sebuah selebaran maupun pengumuman yang terpasang di papan info kampus. Banyak kekurangan yang sering terjadi dengan cara konvensional tersebut, yaitu kertas selebaran yang sering hilang maupun tersobek sebelum informasi tersebut sampai kepada mahasiswa sebagai sasaran utama dari informasi yang terdapat di dalam pengumuman tersebut. Selain itu, mahasiswa juga direpotkan karena harus setiap hari datang ke kampus untuk melihat pengumuman terbaru yang terpasang di papan info.

2. Penelitian yang di lakukan oleh Edhy Sutanta ${ }^{1}$, Khabib Mustofa ${ }^{2}$ pada tahun 2012 yang berjudul "Kebutuhan Web Service Untuk Sinkronisasi Data Antar Sistem Iinformasi Dalam E-GOV DI PEMKAB BANTUL YOGYAKARTA" membahas tentang Pemkab Bantul yang merupakan bagian wilayah pemerintahan Propinsi DIY telah mengembangkan sebanyak 28 aplikasi sistem informasi untuk untuk mendukung kegiatan administrasi, pengolahan data internal, dan layanan informasi publik. Di samping itu, saat ini Pemkab Bantuk juga sudah mengembangkan dan mengelola website http://bantulkab.go.id/ yang di dalamnya telah dikembangkan sebanyak 33 aplikasi yang sebagian besar dapat diakses dari portal web Pemkab, dan sebagian yang lain merupakan sub domain dalam portal web Pemkab. Berbagai upaya peningkatan pemanfaatan TIK terus dilakukan oleh Pemkab Bantul dalam rangka meningkatkan kualitas e-Gov.

3. Penelitian yang di lakukan oleh Fajar Fani Hartono ${ }^{1)}$, Hendry ${ }^{2)}$, Ramos Somya ${ }^{3)}$ pada tahun 2013 tentang "Aplikasi Reservasi Tiket Bus pada Handphone Android menggunakan Web Service (Studi Kasus: PO. Rosalia Indah)". Mengkaji tentang Penyajian informasi ketersediaan tiket yang masih manual menjadi salah satu permasalahan yang dialami oleh jasa travel karena calon penumpang harus datang ke agen untuk mengetahui ketersediaan tiket. Oleh karena itu perlu adanya suatu aplikasi sistem reservasi.Sistem Reservasi tiket bus digunakan calon penumpang untuk melakukan pemesanan tiket perjalanan tanpa harus datang ke agen. Untuk memudahkan calon penumpang dalam mengakses sistem ini, maka dibangun aplikasi reservasi tiket bus berbasis Android mobile. Android adalah ku mpulan perangkat lunak yang ditujukan bagi perangkat bergerak mencakup sistem operasi. Aplikasi ini berjalan pada platform Android dan berintegrasi dengan aplikasi yang berada di server. Server dibangun berbasis web yang memanfaat kan web service.

4. Penelitian yang di lakukan oleh Edhy Sutanta and Mustofa, Khabib pada tahun 2012 tentang "Strategi Pengembangan Web Service Untuk Integrasi Inter Sistem E-GOVERNMENT Di Pemerintah Kabupaten Bantul Yogyakarta". Mengkaji tentang Pengembangan e-Government di Kabupaten Bantul yang dikembangkan oleh Kantor Pengolahan Data Telematika (Kementerian yang). 
Sampai saat ini ada 27 sistem informasi dan 33 situs telah dikembangkan dan diimplementasikan. Masalah yang dihadapi saat ini adalah bagaimana mengintegrasikan sistem antara sistem yang ada dapat memberikan informasi yang akurat dan konsisten. Masalah ini muncul karena masing-masing sistem menggunakan secara terpisah basis data. Makalah ini membahas gagasan strategi pengembangan layanan web untuk integrasi sistem antar di Kabupaten Bantul eGovernment.

5. Penelitian Yang Di lakukakn oleh Tegar M. Aji ${ }^{1}$, Djalal Er Riyanto ${ }^{2}$, Helmie Arif Wibawa ${ }^{2}$ pada tahun 2012 tentang "Penerapan Web Services Dan Regular Expression Untuk Verifikasi Alamat Berbasis Hasil Penelusuran Situs Kodepos PT POS INDONESIA" mengkaji tentang Situs Kodepos PT Pos Indonesia (KPPI) merupakan situs yang menyediakan fasilitas penelusuran data alamat dan kodepos berdasarkan input lokasi dan kota. Data kodepos dan kelengkapan alamat lainnya pada situs KPPI ini diperlukan oleh berbagai pihak. Namun demikian, situs KPPI belum menerapkan antarmuka yang memungkinkan datanya dapat diakses oleh situs lain.

Berdasarkan lima literature review yang telah di kutip di atas yang mengkaji mengenai pemanfaatan Web Service untuk membantu dalam pengiriman data sehingga memungkinkan aplikasi Web Service tersebut dapat berinteraksi dengan sistem lain.

\section{HASIL DAN PEMBAHASAN}

Untuk menindak lanjuti masalah yang ada, pembuatan file JSON untuk mendukung pengembangan aplikasi maka pemecahan masalah yang akan di lakukan adalah dengan menerapkan metode RESTful API karena data yang telah di ambil melalui database sepenuhnya telah terputus dari database. Maka data yang telah di ambil akan di ubah menjadi file-file yang dapat di unduh oleh mahasiswa tanpa terkoneksi langsung dengan database. Sehingga banyak keuntungan yang di peroleh di antaranya adalah mahasiswa mudah dalam proses pengambilan data karena tidak perlu lagi meminta username dan password untuk mengakses database, mahasiswa cukup mengakses web service yang tersedia dan semua data data tentang perguruan tinggi dapat di unduh sebanyak apapun dan kapanpun.

Menurut Hakim (2012:1) Java Script Object Notation (JSON) adalah format pertukaran data yang ditemukan oleh Douglas Crockford pada tahun 2006 yang memiliki ukuran data yang lebih kecil serta waktu proses yang lebih cepat dibandingkan dengan XML yang sudah terlebih dulu ada. Sebelum ditemukannya JSON, web service yang ada menggunakan XML sebagai media pertukaran data, yang sudah menjadi standar dan umum digunakan oleh para programmer, namun sekarang JSON bisa juga digunakan sebagai media alternatif pertukaran data didalam web service. 
Dan kelebihan selanjutnya adalah meningkatnya kemanan database, karna file file yang telah di ubah ke dalam JSON tidak terkoneksi dengan database sehingga jika sewaktu waktu terjadi hal-hal yang tidak di ingin kan seperti rusaknya data atau sistem di retas oleh pihak yang tidak bertanggung jawab data asli tetap aman tersimpan pada database tanpa mengalami gangguan sedikitpun. Berikut adalah diagram-diagram yang membantu dalam penggambaran sistem untuk memudahkan dalam analisa sistem :

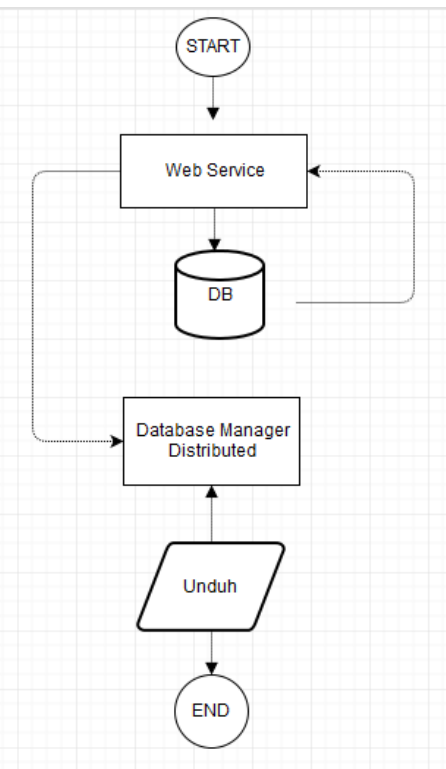

Gambar 2. Flow Chart Web Service.

Flowchart di atas menjelaskan tentang tahapan web service dalam mengambil data dari database, selanjutnya database mengirimkan data ke databse manager distributed yang bertugas mengubah data tersebut kedalam bentuk file JSON untuk di letakan pada sebuah direktori dan siap di unduh oleh mahasiswa.

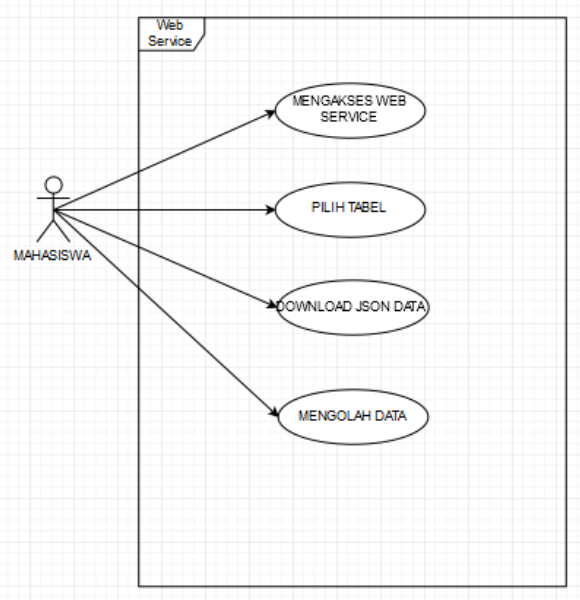

Gambar 3. Use Case Web Service 
Usecase diagram di atas menjelaskan tentang proses mahasiswa mengambil data melalui web service, mahasiswa mengakses web service lalu mencari sumber data dari tabel yang tersedia, selanjutnya jika sumber data sudah di temukan mahsiswa dapat langsung mengunduh data tersebut dan dapat langsung di olah untuk membantu pengembangan aplikasi yang sedang di buat.

\subsection{Implementasi}

\section{a. Web Service Perguruan Tinggi Raharja.}

Dalam implementasi sederhana bisa berarti eksekusi atau aplikasi.Browne dan Wildavsky (Usman, 2004: 7) berpendapat bahwa "implementasi adalah perluasan aktivitas menyesuaikan satu sama lain"

Proses Pertama yang harus di lakukan untuk mengambil data melalui web Service adalah mencari sumber data, berikut contoh sumber data yang dapat di jadikan contoh adalah web service perguruan tinggi raharja. Rapi.raharja.me. Pada implementasi ini berisikan tahapan-tahapan menggambil sebuah data melalui web service.

\section{Selamat Datang, Rapi}
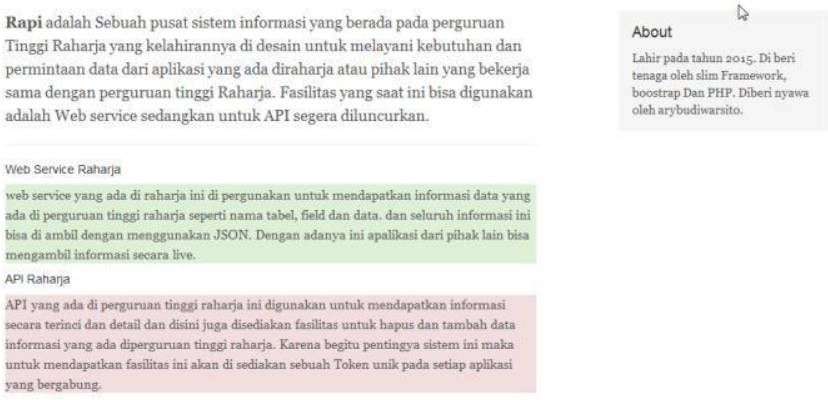

Gambar 4. Web Service Raharja

\section{b. Tampilan Tabel Web Service}

Di bawah ini adalah tampilan tabel yang berisi data-data yang berhubungan dengan dosen, data mahasiswa dan data mahasiswa. 


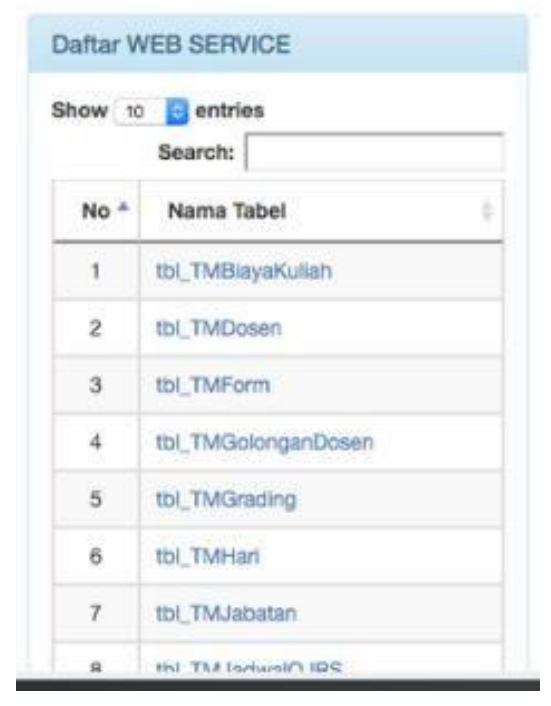

Gambar 5. Tabel Web Service

\section{c. Tampilan Struktur Tabel}

Di bawah ini adalah tampilan stuktur tabel yang berisi No, Nama Field, Type, dan panjang. Struktur ini dapat membantu juga dalam perancangan SQL.

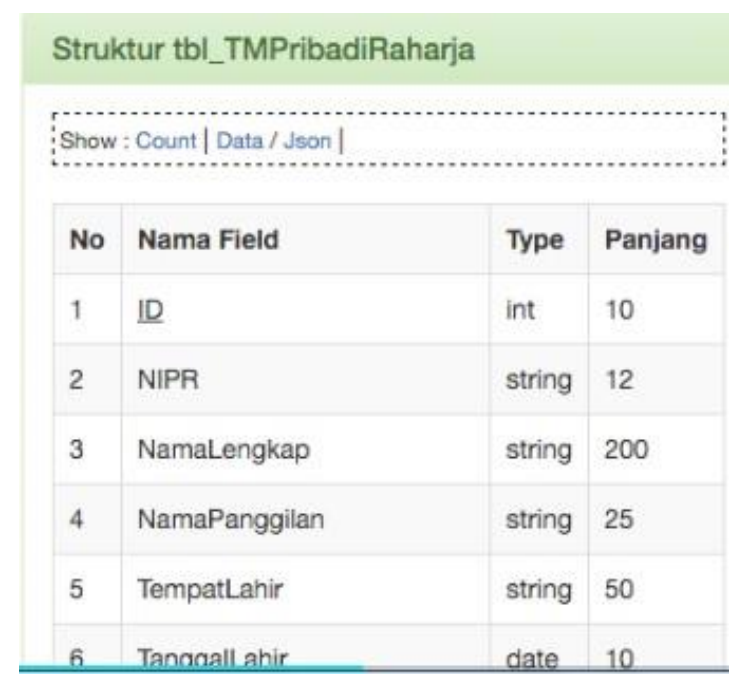

Gambar 6. Tampilan Struktur Tabel Web Service

\section{d. Tampilan JSON}

JSON (JavaScript Object Notation) adalah format pertukaran data yang sangat ringan serta lebih mudah dibaca dan ditulis oleh manusia, sehingga mudah untuk diterjemahkan dan dibuat (generate) oleh komputer. Pada umumnya, semua bahasa 
pemprograman modern mendukung untuk struktur data ini dalam bentuk yang sama maupun komponen yang berlainan. Hal ini pantas disebut demikian karena format data mudah dipertukarkan dengan bahasa-bahasa pemprograman yang juga berdasarkan pada struktur data ini.

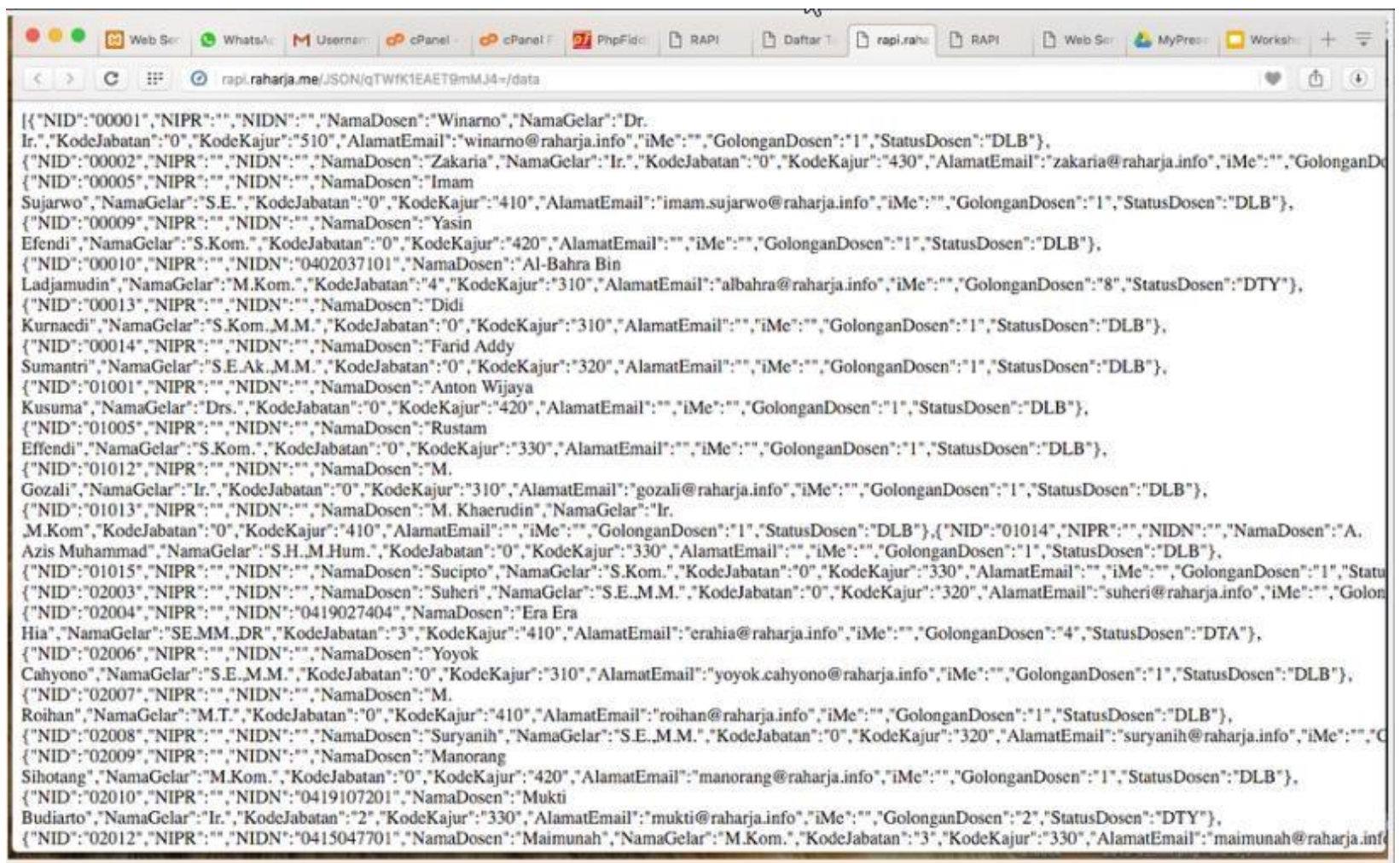

Gambar 7. Contoh Data Dari Tabel Dosen

\section{e. Script untuk mengambil informasi dari Website}

Script ini berfungsi untuk mengambil informasi dari website. sedangkan json_decode berfungsi untuk mengubah bentuk JSON ke dalam bentuk Array.

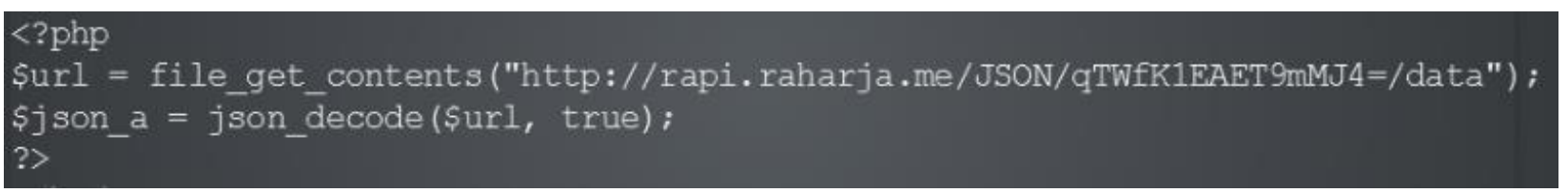

Gambar 8. Metode get JSON

\section{f. Tampilan Array dari tabel RAPI}

Setelah data JSON mengalami proses decode maka isi file JSON tersebut akan di bongkar dan menghasilkan sebuah array seperti gambar di bawah ini. 


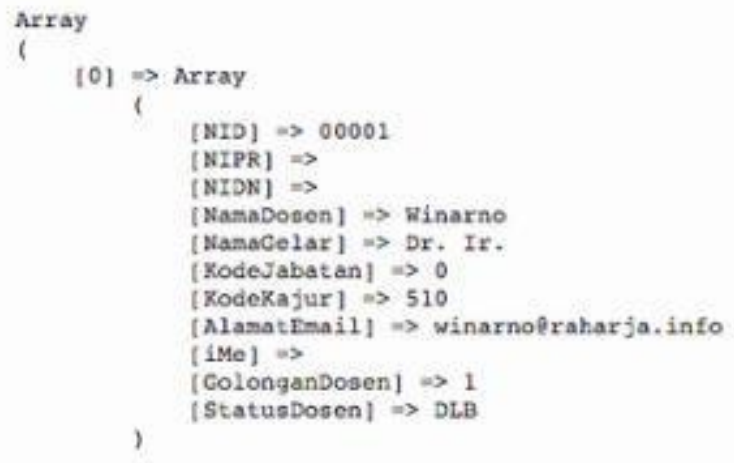

Gambar 9. Tampilan Array

\section{g. Penggunaan Data JSON untuk Aplikasi lain}

Disini saya coba untuk menerapkan JSON untuk apikasi yang telah di gunakan di perguruan tinggi raharja, dimana aplikasi tersebut menggunakan Web Service sebagai media untuk mendapatkan data mahasiswa pada perguruan tinggi tersebut yang nantinya aplikasi tersebut akan di gunakan oleh mahasiswa untuk mensubmit hasil jurnal mereka untuk di vaidasi dan selanjutnya point yang di dapat dari jurnal tersebut akan tampil di profile masing-masing mahasiswa. Berikut adaah data yang di manfaatkan untuk aplikasi tersebut:

\{"NIM":"1312476374","NIPR":"20169508081332","NamaDepan":"Ajeng","NamaBelakang":"Ananda

","NamaPanggilan":"Ajeng","TempatLahir":"Jakarta","Tanggall_ahir":"1995-08-08","KTP":"3603284808950003","KodeNegara":"ID","JenisKelamin":"P","StatusPerkawinan":"0","AlamatTinggal":"J1. Bidar VII No. 16 Kelapa Dua Tangerang","KodePosTinggal":"15143","ProvinsiTinggal":"Jawa Barat","KotaTinggal":"Kabupaten Tangerang","Jenis Tinggal":"Bersama Orang Tua","AlamatSurat":"Jin. Bidar VII No. 16 RT 04 RW 07 Kelapa Dua Tangerang","KodePosSurat":"15143","ProvinsiSurat":"Jawa Barat","KotaSurat":"Kabupaten Tangerang","AlamatEmail":"ajeng @araharja.info","PersonalWebsite":"'http:Wajeng.ilearning.mel/wp-admin

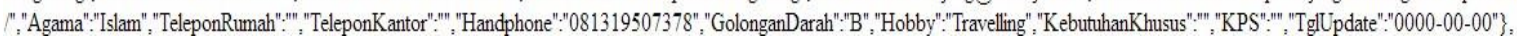

Gambar 10. Pemanfaatan data JSON dari Web Service http://rapi.raharja.me/

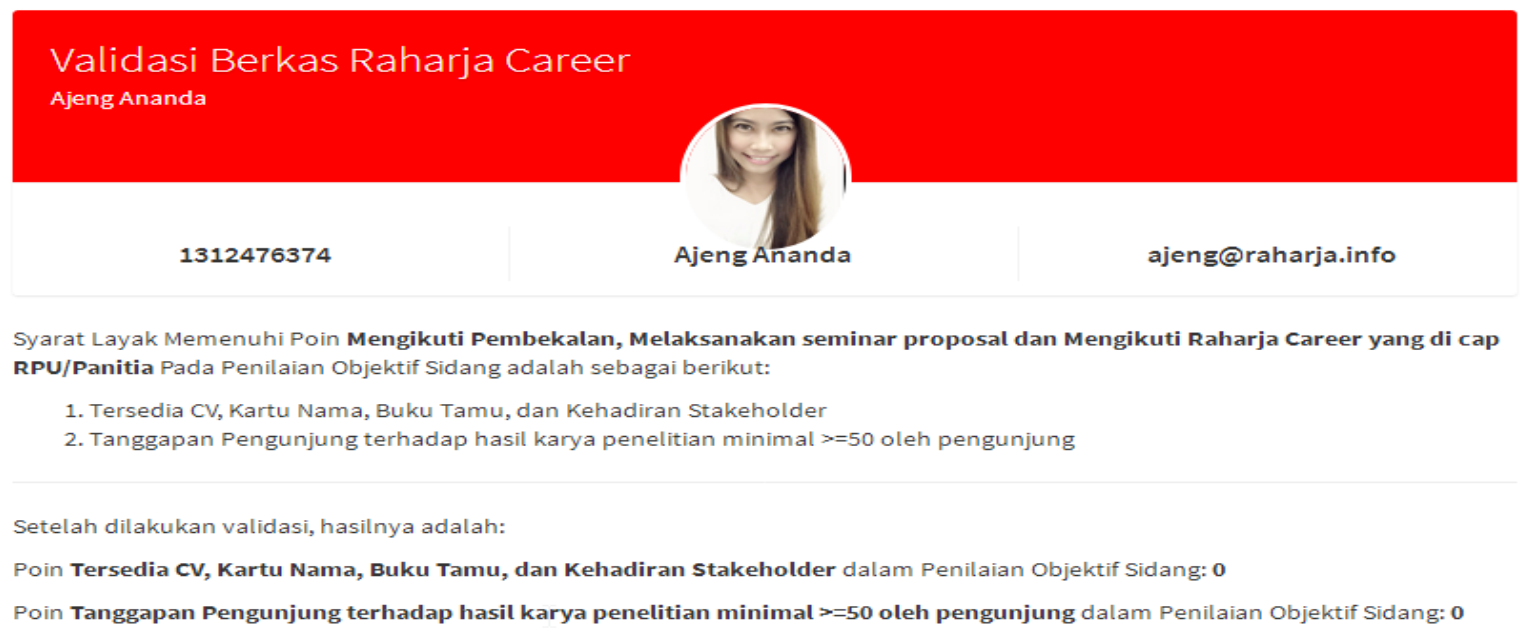

Gambar 11. Hasil pemanfaatan data JSON untuk PESSTA+ 


\section{KESIMPULAN}

Dari hasil observasi di atas dapat di ambil kesimpulan bahwa pengguaan JSON sebagai media pertukaran data yang ringan dan mudah di terjemahkan oleh komputer maupun manusia di karenakan kombinasi kode yang membentuk array mudah di buat dan dipahami. Dan JSON itu sendiri sangat berguna untuk mendukung perancangan aplikasi pada perguruan tinggi dengan menggunakan metode REST full API dan Web Service.

\section{SARAN}

Web interaktif, tentunya melibatkan pertukaran data antara server dan browser, format data yang dipergunakan sebaiknya bersifat universal, ringan, dan mudah diimplementasikan.

\section{DAFTAR PUSTAKA}

[1]. Wijaya, I Wayan Gede Suma. 2012. "Penerapan Web Service Pada Aplikasi Sistem Akademik Pada Platform Sistem Operasi Mobile Android” Teknik Informatika, STIKOM PGRI Banyuwangi Jl. Jend. A Yani 82, Banyuwangi, Jawa Timur, 68416

[2]. Sutanta., Edhy, Khabib Mustofa. 2012 "Kebutuhan Web Service Untuk Sinkronisasi Data Antar Sistem Iinformasi Dalam E-GOV DI PEMKAB BANTUL YOG YAKARTA” JURTIK, STMIK. Bandung.

[3]. Hartono, Fajar., Fani, Hendry, Ramos Somya 2013 “Aplikasi Reservasi Tiket Bus pada Handphone Android menggunakan Web Service (Studi Kasus: PO. Rosalia Indah)".

[4]. Sutanta, Edhy and Mustofa, Khabib. 2012 "Strategi Pengembangan Web Service Untuk Integrasi Inter Sistem E-GOVERNMENT Di Pemerintah Kabupaten Bantul Yogyakarta”. SISFOTENIKA, STMIK Pontianak

[5]. Aji, Tegar M., Djalal Er Riyanto, Helmie Arif Wibawa. 2012 "Penerapan Web Services Dan Regular Expression Untuk Verifikasi Alamat Berbasis Hasil Penelusuran Situs Kodepos PT POS INDONESIA" Journal Of Infomatics And Technology Vol 1, No 1, p38-51 